\title{
Lung cancer staging: imagine fewer images
}

\author{
To the Editor:
}

The update on lung cancer staging published by the European Respiratory Journal [1] is a welcome overview of a field characterised by fast evolution of therapeutic modalities. The accurate staging of lung cancer is of utmost importance for an optimal outcome. Since value of care incorporates outcome over cost as a surrogate of the quality achieved [2], one must be very attentive in recommending the necessary staging investigations.

We take this notion further regarding the recommendation on the imaging of the central nervous system in patients with non-small cell lung cancer. RAMI-PORTA et al. [1] recommend cerebral imaging in all patients with curative therapeutic options, preferably by magnetic resonance imaging (MRI).

Although no one doubts about the prognostic importance of the detection of brain metastasis, we should also consider the impact of the investigation on the final outcome beyond the individual-patient level. Many older and more recent studies investigated the prevalence of occult brain metastasis [3-5]. Tumour size, presence of nodal metastasis and tumour type all appear predictive [6]. The overall prevalence in patients in whom a resection is planned ranges from $1 \%$ to $3 \%[3,4,6]$. MRI is marginally better than contrast-enhanced computed tomography of the brain [3]. Most data originated before fluorodeoxyglucose positron emission tomography was incorporated into routine practice, meaning that the aforementioned figures are subject to selection bias. In patients with locally advanced lung cancer, the prevalence is $>15 \%$ [5]. Besides prevalence, one should also consider cost. A recent evaluation in patients with resectable lung cancer estimated that $32 \%$ of the staging costs were from brain MRI although the prevalence of metastasis was only $1.3 \%$ [4]. Additional imaging can also cause treatment delays and increase the psychological burden on the patient. There are several reports on incidental or of false-positive findings leading to the denial of curative therapy.

In stage III, the indication for brain imaging is definite in all guidelines, taking into account the burden of multimodality treatments. There is, however, remarkable inconsistency in recommendations for patients with stages I-II. The American College of Chest Physicians recommends the brain should not be scanned in these patients [7]. The National Comprehensive Cancer Network guideline released in 2018 has a recommendation for stage IB-II but not for stage IA [8]. The National Institute for Health and Care Excellence (NICE) guidelines (2011) and European Society for Medical Oncology guidelines (2017) state that MRI of the brain might be useful for patients with curative intent, with NICE adding a comment that this is particularly the case for patients with stage III lung cancer $[9,10]$.

In our opinion, and contrasting with the recommendation to perform brain MRI for all patients [1], a more restrictive strategy is defensible, especially for those with a low risk of developing brain metastasis. There is a clear unmet need for prospective research in order to optimise the value of care delivered in these patients suffering a severe lung disease.

Kurt G. Tournoy ${ }^{1,2}$ and Jan P. Van Meerbeeck ${ }^{3}$

${ }^{1}$ Dept of Respiratory Medicine, Onze-Lieve-Vrouw Ziekenhuis Aalst, Aalst, Belgium. ${ }^{2}$ Faculty of Medicine and Life Sciences, Ghent University, Ghent, Belgium. ${ }^{3}$ Dept of Respiratory Medicine, Antwerp University Hospital, Edegem, Belgium.

Correspondence: Kurt G. Tournoy, Dept of Respiratory Medicine, Onze-Lieve-Vrouw Ziekenhuis Aalst, Building X-2, Moorselbaan 164, 9300 Aalst, Belgium. E-mail: kurt.tournoy@olvz-aalst.be

Received: June 112018 | Accepted after revision: June 232018

Conflict of interest: None declared.

@ERSpublications

There is no place for reflex brain MRI in any patient with early stage non-small cell lung cancer being considered for a therapy with curative intent http://ow.ly/I5O530kI5vQ

Cite this article as: Tournoy KG, Van Meerbeeck JP. Lung cancer staging: imagine fewer images. Eur Respir J 2018; 52: 1801093 [https://doi.org/10.1183/13993003.01093-2018]. 


\section{References}

1 Rami-Porta R, Call S, Dooms C, et al. Lung cancer staging: a concise update. Eur Respir J 2018; 51 : 1800190.

2 Porter ME. What is value in health care? N Engl J Med 2010; 363: 2477-2481.

3 Yokoi K, Kamiya N, Matsuguma H, et al. Detection of brain metastasis in potentially operable non-small cell lung cancer: a comparison of CT and MRI. Chest 1999; 115: 714-719.

4 Vernon J, Andruszkiewicz N, Schneider L, et al. Comprehensive clinical staging for resectable lung cancer: clinicopathological correlations and the role of brain MRI. J Thorac Oncol 2016; 11: 1970-1975.

5 Hochstenbag MM, Twijnstra A, Hofman P, et al. MR-imaging of the brain of neurologic asymptomatic patients with large cell or adenocarcinoma of the lung. Does it influence prognosis and treatment? Lung Cancer 2003; 42: $189-193$.

6 Diaz ME, Debowski M, Hukins C, et al. Non-small cell lung cancer brain metastasis screening in the era of positron emission tomography-CT staging: current practice and outcomes. J Med Imag Radiat Oncol 2018; 62: 383-388.

7 Silvestri GA, Gonzalez AV, Jantz MA, et al. Methods for staging non-small cell lung cancer: diagnosis and management of lung cancer, 3rd ed: American College of Chest Physicians evidence-based clinical practice guidelines. Chest 2013; 143: Suppl., e211S-e250S.

8 National Comprehensive Cancer Network. Non-small cell lung cancer. Fort Washington, NCCN, 2018.

9 Postmus PE, Kerr KM, Oudkerk M, et al. Early and locally advanced non-small-cell lung cancer (NSCLC): ESMO Clinical Practice Guidelines for diagnosis, treatment and follow-up. Ann Oncol 2017; 28: Suppl. 4, iv1-iv21.

10 National Institute for Health and Care Excellence. Lung cancer: diagnosis and management. https://nice.org.uk/ guidance/cg121. Date last updated: April 2011.

From the authors:

We would like to thank K.G. Tournoy and J.P. Van Meerbeeck for their interest in our article [1]. In their letter, they raise important points that highlight the controversy surrounding the value of preoperative brain magnetic resonance imaging (MRI) in patients who can be considered for curative therapeutic option. We agree with them that accurate staging is essential for an optimal outcome.

We recommend searching for brain metastases in all patients with curative treatment options. VeRNON et al. [2] showed that MRI is a low-yield and high-cost intervention in the population that was analysed, and therefore the role of MRI as a routine exam should be questioned. Conversely, the article published by O'DowD et al. [3] showed that $71 \%$ of patients who developed brain metastases might have been detected if they had been scanned with MRI prior to surgical intervention. They found a $6.3 \%$ incidence of postoperative brain metastases, with the majority appearing within 12 months of surgery. These patients were more likely to have adenocarcinoma and an early stage ( $73 \%$ stage I or II). The European Society of Medical Oncology guidelines recommend screening for brain metastases by MRI in patients considered for curative therapy [4].

However, a recent study by MiLlon et al. [5] demonstrated that MRI is better than computed tomography (CT) plus new reconstruction techniques. By adding MRI to positron emission tomography (PET)/CT, brain metastases can be detected in an additional 7\% patients [6]. MRI is better than PET alone in the diagnosis of brain metastases as showed by Deuschl et al. [7]. These articles demonstrated that MRI remains the gold standard for detecting brain metastases [5-7].

To conclude, we think that to perform brain MRI is the optimal staging for patients with curative therapeutic options. However, this ideal recommendation will depend on the availability and the resources of each institution, and we concur with K.G. Tournoy and J.P. Van Meerbeeck that a more restrictive indication may apply in particular circumstances.

Ivan Vollmer ${ }^{1}$, Marcelo Sánchez ${ }^{1}$ and Ramón Rami-Porta ${ }^{2,3}$

${ }^{1}$ Centre of Imaging Diagnosis, Radiology Dept, Hospital Clínic, University of Barcelona, Barcelona, Spain. ${ }^{2}$ Dept of Thoracic Surgery, Hospital Universitari Mutua Terrassa, University of Barcelona, Barcelona, Spain. ${ }^{3}$ Network of Centres for Biomedical Research in Respiratory Diseases (CIBERES) Lung Cancer Group, Barcelona, Spain.

@ERSpublications

Brain imaging with MRI is recommended for all lung cancer patients candidates for radical treatment http://ow.ly/FkgL3016b6o

Cite this article as: Vollmer I, Sánchez M, Rami-Porta R. Lung cancer staging: imagine fewer images. Eur Respir J 2018; 52: 1801314 [https://doi.org/10.1183/13993003.01314-2018]. 
Correspondence: Ramón Rami-Porta, Dept of Thoracic Surgery, Hospital Universitari Mútua Terrassa, Plaza Dr Robert 5 , 08221 Terrassa, Barcelona, Spain. E-mail: rramip@yahoo.es

Received: July 132018 | Accepted: July 192018

Conflict of interest: None declared.

\section{References}

1 Rami-Porta R, Call S, Dooms C, et al. Lung cancer staging: a concise update. Eur Respir J 2018; 51: 1800190.

2 Vernon J, Andruszliewicz N, Schneidet L, et al. Comprehensive clinical staging for resectable lung cancer: clinocpathological correlations and the role of brain MRI. J Thorac Oncol 2016; 11: 1970-1975.

3 O’Dowd EL, Kumaran M, Anwar S, et al. Brain metastases following radical surgical treatment of non-small cell lung cancer: is preoperative brain imaging important? Lung Cancer 2014; 86: 185-189.

4 Postmus PE, Kerr KM, Oudkerk M, et al. Early and locally advanced non-small cell lung cancer (NSCLC): ESMO clinical practice guidelines for diagnosis, treatment and follow-up. Ann Oncol 2017; 28: iv1-iv21.

5 Millon D, Byl D, Collard P, et al. Could new reconstruction CT techniques challenge MRI for the detection of brain metastases in the context of initial lung cancer staging? Eur Radiol 2018; 28: 770-779.

6 Lee HY, Lee KS, Kim BT, et al. Diagnostic efficacy of PET/CT plus brain MR imaging for detection of extrathoracic metastases in patients with lung adenocarcinoma. J Korean Med Sci 2009; 24: 1132-1138.

7 Deuschl C, Nensa F, Grueneisen J, et al. Diagnostic impact of integrated 18F-FDG PET/MRI in cerebral staging of patients with non-small cell lung cancer. Acta Radiol 2017; 58: 991-996. 